\title{
Aculturación, transculturación, mestizaje: metáforas y espejos en la historiografía latinoamericana
}

\author{
Acculturation, Transculturation, Miscegenation: Metaphors \\ and Mirrors in Latin American Historiography \\ Aculturação, transculturação, mestiçagem: metáforas \\ e espelhos na historiografia latinoamericana
}

\section{Héctor Pérez-Brignoli}

UNIVERSIDAD DE COSTA RICA, COSTA RICA

Profesor de la Universidad de Costa Rica y Doctor en Historia por la

Université de Paris I. Entre sus principales publicaciones se destacan

La población de Costa Rica, 1750-2000. Una historia experimental

(Editorial Universidad de Costa Rica, 2010), Los 50 años de la FLACSO

y el desarrollo de las Ciencias Sociales en América Latina (FLACSO

- Editorial Juricentro, 2008) y el Historical Atlas of Central America

(University of Oklahoma Press, 2003; en coautoría con Carolyn Hall y

John V. Cotter [cartógrafo]). Correo electrónico: hector.perez@ucr.ac.cr

\begin{abstract}
Artículo de reflexión
Documento accesible en línea desde la siguiente dirección: http://revistas.javeriana.edu.co

El artículo forma parte de un proyecto de investigación desarrollado en la Universidad de Costa Rica. La versión original del texto se presentó en el taller La Producción, Traducción y Apropiación Transregional de Saberes: Actores, Instituciones y Discursos, organizado por el Instituto Ibero-Americano en Berlín, el 10 y 11 de octubre de 2014.
\end{abstract}




\section{Resumen}

Se discuten los conceptos de aculturación y transculturación a partir de la obra de Fernando Ortiz, y se estudia su uso en la historiografía latinoamericana. Ambos conceptos se utilizan, por lo general, de forma intercambiable y los historiadores no se destacan mucho por su precisión conceptual.

Palabras clave: aculturación; transculturación; historiografía latinoamericana

\section{Abstract}

We discuss the concepts of acculturation and transculturation based on the works of Fernando Ortiz, and we study their use in Latin American historiography. Both concepts are generally used interchangeably and historians do not generally stand out for their conceptual accuracy.

Keywords: acculturation; transculturation; Latin American historiography

\section{Resumo}

Os conceitos de aculturação e transculturação são discutidos a partir da obra de Fernando Ortiz e estudado o seu uso na historiografia latinoamericana. Ambos os conceitos utilizamse, geralmente, de forma intercambiável e os historiadores não se destacam exatamente pela sua precisão conceptual.

Palavras-chave: aculturação; transculturação; historiografia latinoamericana

\section{Cómo citar este artículo:}

Pérez-Brignoli, Héctor. "Aculturación, transculturación, mestizaje: metáforas y espejos en la historiografía latinoamericana". Cuadernos de Literatura 21.41 (2017): 96-113. https://doi.org/10.11144/Javeriana.cl21-41.atmm 
Aculturación y transculturación son conceptos que provienen, como bien se sabe, de la antropología. El primero fue utilizado desde finales del siglo XIX, pero solo obtuvo un intento de definición riguroso en la década de 1930 (Redfield, Linton y Herskovits). El segundo fue propuesto en 1940 por el antropólogo cubano Fernando Ortiz, como una noción más pertinente que la de aculturación. La obra de Ortiz fue prologada por Bronislaw Malinowski, quien bendijo el vocablo y le dio así entrada oficial en la capilla de los antropólogos (Ortiz). Sin embargo, salvo algunas excepciones, tanto en la antropología como en la historiografía se siguió utilizando con más frecuencia la noción de aculturación. Ortiz rechazó el concepto de aculturación argumentando su carácter unidireccional: los individuos de la cultura dominada se adaptan, es decir se aculturan, incorporando elementos de la cultura dominante. En su visión, el concepto de transculturación era necesario para incorporar el carácter multidireccional de los contactos culturales. Pero como sostuvo por ejemplo Gonzalo Aguirre Beltrán, la idea de la aculturación no riñe en sí con la de contactos en múltiples direcciones; se trataría pues de una simple cuestión de buena definición. Es innegable, sin embargo, que en el concepto de aculturación hay, por el uso que se le ha dado, una carga negativa e inconsciente, reflejada bien en la frase - o, más bien el grito de José María Arguedas-: "yo no soy un aculturado" (Arguedas). En los procesos de aculturación - aunque podría argumentarse que lo mismo ocurre en los procesos de transculturación - casi siempre hay una cultura que aparece como dominante y más fuerte. Los contactos culturales están tejidos invariablemente sobre relaciones de poder. Antes de proseguir con ejemplos de la historiografía conviene reflexionar sobre la naturaleza de los contactos y fusiones culturales.

En su esfuerzo por definir la cubanidad, es decir la manera de ser de lo cubano, Fernando Ortiz utilizó la metáfora del ajiaco. ${ }^{1}$ El ajiaco es

el guiso más típico y más complejo hecho de varias especies de legumbres ... y de trozos de carnes diversas; todo lo cual se cocina con agua en hervor hasta producirse un caldo muy grueso y suculento y se sazona con el cubanísimo ají que le da su nombre . . . La imagen del ajiaco criollo nos simboliza bien la formación del pueblo cubano ... ante todo una cazuela abierta. (Etnia 5 )

Y todos los ingredientes, desde los vegetales hasta las carnes, las especias y los utensilios de cocción, reflejan la mezcla cultural cubana: indígena, africana,

1 Conferencia sobre los factores humanos de la cubanidad, pronunciada por Ortiz en la Universidad de La Habana en noviembre de 1942 (Etnia 3-20). 
castellana, europea, asiática y anglosajona. Ahora bien, y este es el rasgo más original de la formulación de Ortiz,

la cubanidad [no hay] que buscarla en esa salsa de nueva y sintética suculencia formada por la fusión de los linajes humanos desleídos en Cuba... Lo característico de Cuba es que, siendo ajiaco, su pueblo no es un guiso hecho, sino una constante cocedura. Desde que amanece su historia hasta las horas que van corriendo, siempre en la olla de Cuba es un renovado entrar de raíces, frutos y carnes exógenas, un incesante borbor de heterogéneas sustancias. De ahí que su composición cambie y la cubanidad tenga sabor y consistencia distintos según sea catado en lo profundo o en la panza de la olla o en su boca, donde las viandas aún están crudas y burbujea el caldo claro[.] . . Puede decirse que, en rigor, en todo pueblo ocurre algo semejante. (Etnia 5 )

La metáfora del ajiaco permite insistir en la transculturación como proceso, es decir, como un fenómeno en perpetuo movimiento, que por ende desafía cualquier definición rígida. La cubanidad solo se puede entender como este perpetuo movimiento, lo que conduce también, en la concepción de Ortiz, a rechazar cualquier definición esencialista de la identidad cultural.

Contrapunteo del tabaco y el azúcar es el estudio más famoso y complejo de Ortiz; trabajo en el que, como ya se dijo, introdujo específicamente el concepto de transculturación. Pero el concepto está siempre presente a lo largo de toda su obra. Mencionemos solamente algunos ejemplos. En un texto publicado en 1952 estudió la transculturación blanca en los tambores de los negros cubanos, ${ }^{2}$ mientras que en un artículo impreso en $195^{\circ}$ analizaba la influencia afrocubana en el jazz norteamericano (Etnia 247-251). La pintura de Wifredo Lam le inspira un magnífico estudio en el que especifica la naturaleza del tan comentado mestizaje plástico presente en la obra del artista cubano (Wifredo Lam). De padre chino y madre afrocubana, pero nacido y criado en la Cuba rural, en la villa de Sagua, la paleta de Lam, formada técnicamente en Madrid y París, plasmaba herencias, experiencias y visiones muy diversas y complejas, unificadas por un destierro permanente:

es un refugiado y en todas partes un hombre marginal y adolorido por sus frustraciones, que en los éxtasis de su arte busca la catarsis a sus tensiones íntimas. Como hombre, como artista, como mestizo y como ciudadano del mundo; de este mundo resquebrajado y entenebrecido como castillo en ruinas, al que están

2 El estudio es reproducido parcialmente en el trabajo de Ortiz de 1993 (Etnia 181-188). Con transculturación blanca el autor se refiere a cómo, en la música cubana, se introducen y transforman los timbales europeos. 
volviendo los duendes, las estantiguas, las 'almas en pena,' así de las alucinadoras supersticiones como de las pavorosas realidades. (Wifredo Lam)

Obviamente es en Contrapunteo del tabaco y el azúcar ${ }^{3}$ que Ortiz desarrolló más el concepto de transculturación. Esta obra combina una investigación histórica y antropológica con una expresión literaria ensayística poco usual. El contrapunteo significa, en Cuba, una disputa o dichos picantes o acalorados entre dos o más personas (Contrapunteo 26). La expresión también tiene un significado musical que incluye elementos hispanos y africanos, y el tratamiento de Ortiz alcanza a la vez un carácter poético. La disputa entre don Tabaco y doña Azúcar recoge ecos del Libro de Buen Amor del Arcipreste de Hita (13301343), en el que, como se sabe, se presenta un contrapunteo entre el Carnaval y la Cuaresma. Otros contrapuntos aparecen en las disputas teológicas, y están también presentes en muchos textos de la literatura clásica española. Ortiz escoge así una expresión literaria de gran tradición, pero inusual en el siglo $\mathrm{XX}$, que le viene de perlas para captar la ambigüedad y complejidad del tema principal, rehuyendo a la linealidad y rechazando las definiciones esencialistas. El libro de Ortiz tiene dos partes: la primera es un ensayo general dividido en 15 secciones sin título, pero que incluyen múltiples referencias a los capítulos adicionales que conforman la segunda parte del libro. Esta segunda parte, por otro lado, la conforman 25 capítulos muy eruditos sobre temas diversos que apoyan las tesis sostenidas en la primera parte. Dichos capítulos se agrupan bajo dos temáticas: "historia, etnografía y transculturación del tabaco habano" e "inicios del azúcar y de la esclavitud de negros en Cuba". La manera como está estructurado el texto permite varias lecturas posibles: una lineal, en la que se procede en orden de la primera a la segunda parte, y otra dialógica, organizada a partir de las diferentes bifurcaciones posibles entre las partes. El contrapunteo parte de oposiciones binarias, pero muestra enseguida las relaciones complejas y cambiantes que se dan entre los opuestos. La parte inicial propone una interpretación, luego de examinar, a lo largo de varios siglos, el contraste existente entre el cultivo de la caña de azúcar y el del tabaco, y sus consecuencias económicas, sociales y culturales con base en cuatro ejes diferentes: la tierra, la máquina, el trabajo y el dinero (Contrapunteo 139). La historia cubana y el perfil de su sociedad y su cultura gira, de manera inseparable, en torno a los dos productos. Al final, el texto llega a decir que "Cuba 
tuvo dos orgullos paralelos, síntesis de este curiosísimo contraste, el ser el país que producía el azúcar en más cantidad y el tabaco en más calidad. El primero fue desvanecido; el segundo nadie se lo puede quitar". Pero las máquinas y el capitalismo financiero "han ido aplanando sus diferencias, deshumanizando sus economías y equiparando más y más sus problemas" (249-250). Así todo parece terminar en un feliz matrimonio, expresado en la trinidad cubana: tabaco, azúcar y alcohol (Ibid.).

La primera parte del libro de Ortiz despliega pues una interpretación de la historia cubana a través del contrapunteo de los dos productos. La segunda parte incluye una gran cantidad de datos heterogéneos que apoyan los argumentos de la primera parte. En el capítulo II de la segunda parte, Ortiz expone el concepto de transculturación como una noción clave para entender la naturaleza y alcances del contrapunteo. Enrico Mario Santí considera que el contrapunteo es la superficie manifiesta, la historia tal como se la percibe en la vida real, mientras que la transculturación es el trasfondo latente, reprimido, de la misma historia (Contrapunteo 79). Los mecanismos profundos de la vida económica nacional, el racismo anti-africano y la violencia profunda generada por la riqueza, entre otros aspectos, cobran así una significación plena.

II

Entre las formas típicas del contacto entre culturas profusamente estudiadas por los historiadores se encuentran los procesos de conquista, dominación y colonización, particularmente referidos al Nuevo Mundo, pero también a África, Asia y Oceanía. El fin del mundo antiguo en Europa, que se dio con las invasiones germánicas, la caída del Imperio Romano de Occidente y la formación de los reinos romano-germánicos en la época que José Luis Romero llamó la Temprana Edad Media, constituye otro tema favorito de los historiadores, y se caracteriza por complejos y profundos fenómenos de aculturación o transculturación (Romero 111-140). Las migraciones a lo largo de la historia, pero en particular durante el periodo de formación de los Estados Unidos, por su magnitud y significación han sido también temas recurrentes, con los conocidos problemas de asimilación e integración de los inmigrantes, confinados entre el gueto y el melting pot.

En estos y muchísimos otros ejemplos a lo largo del tiempo resulta más que obvio que la aculturación (o la transculturación) es un fenómeno asimétrico y que implica relaciones recíprocas que van en múltiples direcciones. Un intento de tipología como el que propuso Nathan Wachtel (2011), basándose en casos de la historia americana, es quizás sucinto, aunque interesante: la aculturación se mueve en gradaciones, desde lo impuesto (conquista) a lo espontáneo (indígenas en las 
fronteras de la colonización), y desde la integración (por ejemplo, Apaches y Araucanos incorporando el caballo y las armas de fuego a su cultura) a la asimilación (los elementos extranjeros acaban por eliminar los componentes indígenas).

En la Antropología que propuso las nociones de aculturación y transculturación imperaba una definición omnicomprensiva de la cultura que la definía como todo lo que es producto de la acción humana, desde los objetos (materiales) hasta las ideas y valores, pasando, claro está, por las instituciones, que son híbridos entre las ideas y los objetos materiales. A esta definición omnicomprensiva de la cultura se agregaba el supuesto de la coherencia. En cada cultura había un núcleo estable, definido por rasgos específicos e identitarios. Nadie expresó esto mejor que Ruth Benedict en su famoso libro Patterns of Culture (1950), cuyas ideas básicas provenían de su no menos famoso estudio sobre la cultura japonesa (1946). Este fue el horizonte intelectual de las formulaciones de la aculturación debidas a Redfield, Herskovitz y Linton, en las décadas de 1930 y 1940. Luego, vino el así llamado giro lingüístico: la cultura fue considerada como un proceso de comunicación simbólica y el énfasis de estudio pasó a los valores. Autores como Clifford Geertz (1973) desarrollaron estas perspectivas en las décadas de 1950 y 1960; ópticas de acuerdo con las que la cultura y, en consecuencia, las formas de aculturación o transculturación, pasaron a ser leídas como textos. Enseguida aparecieron las nociones de objetos híbridos, heterogéneos, en el sentido de que combinaban elementos de diferentes procedencias: estos objetos eran textos, imágenes, rituales, mitos, etc. Algunos autores, como Serge Gruzinski (1999), desarrollaron, para formular este carácter híbrido de los textos (en el sentido amplio, incluyendo imágenes), la idea del pensamiento mestizo. En el mundo globalizado que se impone a finales del siglo XX, todo es hibridez y mestizaje, de modo que se constata una vez más que no existe la pureza cultural, más allá de un esencialismo puramente ideológico, y que en la vida humana todo son conexiones (Amselle, Branchements; Logiques métisses).

III

Volvamos, sin embargo, un poco hacia atrás. En América Latina, la forma más típica de aculturación o transculturación ha sido el mestizaje. Ahora bien, el mestizaje es un fenómeno muy complejo. En la base hubo un mestizaje biológico, producto de la intensa mezcla entre europeos, amerindios, negros africanos y, en menor medida, asiáticos. Al mismo tiempo comenzaron profundos y duraderos fenómenos de aculturación o transculturación. Conviene, antes de proseguir, formular dos acotaciones importantes: 
a) El mestizaje biológico fue, en primer lugar, un proceso extremadamente violento y en parte consubstancial de la conquista misma, pero, a la vez, inseparable de un marco socio-cultural; objetivo que hay que precisar. El número de inmigrantes europeos y africanos y la proporción de sexos resultante en la población total (sex ratio) determinaron condiciones objetivas de posibilidad, filtradas culturalmente a través de los patrones de familia impuestos por la evangelización y de los ideales de familia extensa y linaje predominantes entre los colonizadores españoles y portugueses. Estos patrones resultan más claros cuando se comparan, como lo hizo hace años Susan Socolow, la colonización angloamericana con la ibérica (Socolow). La inmigración europea fue por lo menos tres veces mayor en las Trece Colonias de la América del Norte que en América Latina. A la vez, en la inmigración europea del Atlántico Norte predominaban familias y no hombres solos, de modo que el contacto social y sexual entre europeos y amerindios/africanos fue mucho menor en esos territorios que en la América Latina. La prohibición estricta y temprana de las uniones inter-raciales en las Trece Colonias condicionó fuertemente las posibilidades del mestizaje biológico, y dio marco,junto con el importante peso relativo de los esclavos africanos en las colonias del sur, al desarrollo de una sociedad racialmente segregada. Se conformó así, en los siglos XVII y XVIII, una colonia de poblamiento muy parecida a las que surgirían también en Australia, Canadá y Nueva Zelanda. El contraste no podría ser más fuerte con la América Ibérica, en donde solo en las élites y las comunidades indígenas prevalecen el matrimonio legal y los hijos legítimos. En tanto, en las poblaciones mestizas, que crecen regularmente a lo largo del siglo XVIII y que constituyen al momento de la Independencia la gran mayoría de las poblaciones latinoamericanas, prevalecen las uniones consensuales, y los hogares encabezados por mujeres tiene cierto peso. La ilegitimidad y la mezcla racial son marcas sin duda denigrantes pero reversibles; el dinero finalmente blanquea, algo imposible dentro de la segregación anglosajona.

b) El mestizaje cultural operó en múltiples direcciones, en procesos a menudo caóticos y contradictorios, y no tuvo límites precisos previamente definidos, como es el caso de la hibridez biológica. Mencionemos rápidamente las trayectorias más evidentes de los contactos culturales en Hispanoamérica: los indios adoptan, a su manera, la religión católica, las instituciones españolas, la autoridad y la supremacía de la lengua castellana, la escritura, así como el manejo de animales, cultivos, etc.; los españoles, por su parte, incorporan los productos americanos, ciertas costumbres indígenas, nuevas maneras de ver y de sentir, etc., y se transforman en americanos y, más tarde, en criollos, como bien lo atestigua el testimonio de la Recordación Florida de Fuentes y Guzmán, en Guatemala 
(1969). ${ }^{4}$ Solange Alberro ha estudiado con mucho detalle estas transformaciones en el caso de la Nueva España (1992). Pero hay también situaciones que la sociología de Durkheim consideraría como de anomia: es lo que León-Portilla ha estudiado siguiendo experiencias nahuas, como nepantlismo; es decir, quedar en medio, en una situación en que las antiguas creencias religiosas son condenadas por los frailes católicos sin que los indios logren tampoco entender y asumir la nueva fe predicada por la evangelización (León-Portilla 18-19).

Ahora bien, el mestizaje no solo ha sido un complejo proceso histórico de aculturación o transculturación en múltiples direcciones. También ha sido una ideología poderosa dentro de proyectos más vastos de dominación y transformación social. Esta ambigüedad ha dado lugar a muchas confusiones y malentendidos. La ideología del mestizaje fue una expresión decantada y elaborada del ascenso social de los mestizos, desde la raza cósmica de Vasconcelos hasta el proceso de aculturación cuidadosamente estudiado por Aguirre Beltrán, que permite explicar cómo, bajo la Revolución Mexicana, los campesinos indios fueron convertidos en campesinos mexicanos (1992). Mutatis mutandi, un enfoque parecido fue propuesto por Gilberto Freyre para explicar la formación del pueblo brasileño. El melting pot o crisol de razas enmascara, obviamente, al igual que la igualdad de la ciudadanía plasmada en las Constituciones, las desigualdades de clase; pero esto no implica que el mestizaje sea puro enmascaramiento y que carezca de contenidos a veces subversivos. La igualdad jurídica de la ciudadanía enmascara, sin duda, las diferencias de clase, pero eso no elimina su carácter revolucionario en las sociedades estamentales y esclavistas. Precisamente es esta ambigüedad profunda del mestizaje lo que lo convierte en un concepto clave para entender la dinámica del contacto y el choque de culturas en la historia latinoamericana. Otro aspecto de esta ambigüedad profunda es la asociación, generalmente inconsciente, entre mestizo e impuro, derivada también obviamente del etnocentrismo y el racismo.

IV

Luego de esta ya larga introducción, conviene pasar al uso específico de los conceptos de aculturación y transculturación en la historiografía. Podemos afirmar, en términos generales, que, así como el burgués gentilhombre de Molière hablaba en prosa sin haberse dado cuenta, los historiadores han estudiado incansablemente problemas de aculturación y transculturación sin saberlo, o,

Ver también el texto de Martínez Peláez de 1970, La patria del criollo. Ensayo de interpretación de la realidad colonial guatemalteca. 
en todo caso, sin mencionar dichos conceptos antropológicos. En el Congreso Internacional de Ciencias Históricas de Viena, celebrado en 1965, Alphonse Dupront coordinó una sesión general sobre el tema de la aculturación y presentó un informe detallado en el cual sugería incorporar la noción en el vocabulario de los historiadores (Dupront). Algunos años después, en la antología titulada Faire de l'histoire, Nathan Wachtel publicaba un texto que retomaba las preocupaciones de Dupront, bajo el acápite de nouveaux problèmes de la historiografía (Wachtel). Pero estos pasos hacia adelante no cambiaron mucho el panorama; los historiadores siguieron comportándose como el burgués gentilhombre de Molière.

Una obra como la de Carmagnani sobre la reconstitución de la identidad étnica en Oaxaca, en los siglos XVII y XVIII, es ejemplar en este sentido, aunque el autor nunca use el vocablo de transculturación (Carmagnani). Por su parte, estudiando los mayas de Yucatán, Nancy Farris subraya las limitaciones del concepto de aculturación, empleado corrientemente en la antropología sobre Mesoamérica, y señala la existencia de complejos procesos de mayanización e hispanización (Farris 10-11). Sin embargo, nunca habla de transculturación, ignorando, aparentemente, la obra de Fernando Ortiz. En ese contexto, Nathan Wachtel es uno de los pocos que hicieron un uso consciente de la noción de aculturación, como se observa en su estudio sobre la caída del imperio incaico y la formación de las sociedades andinas.

Veamos el siguiente ejemplo con cierto detalle: "A la desestructuración [provocada por la conquista], los indios responden mediante una aculturación limitada y una inquebrantable fidelidad a la tradición" (Wachtel, Los vencidos 214). El mestizaje se desarrolla rápidamente debido a la escasez de mujeres españolas, pero los mestizos son rechazados tanto por los españoles - temerosos de un alzamiento y la siempre posible alianza entre indios y mestizos-, como por los indígenas. Guamán Poma de Ayala los considera una raza maldita y propone exiliarlos en Chile o en las ciudades, con el fin de proteger a los indios. Para entender este doble rechazo, Wachtel estudia las modalidades indígenas de la aculturación en dos niveles: la vida material y la vida mental (216). La aculturación es visible en la alimentación y el vestuario, mientras que la sociedad española se convierte, para los indios, en la "fuente de todo prestigio" (225). La aculturación mental es más lenta, pero bien visible en el periodo que comprende entre $1570 \mathrm{y}$ 1580 , en el que la lengua y la escritura española se difunden, sobre todo entre los curacas, aunque la masa indígena continuara apegada a las lenguas autóctonas. La evangelización es superficial, así que la sociedad indígena, "desestructurada, no encontró en el cristianismo ningún elemento positivo de reorganización" (229). En el conjunto, hacia 1570 los resultados de la aculturación son limitados: "la 
tradición se impone sobre la aculturación[.] ... Hay deculturación sin verdadera aculturación" (239-242). Para completar el cuadro, Wachtel estudia en detalle dos casos de aculturación a través de los escritos de los cronistas Garcilaso de la Vega y Guamán Poma de Ayala. Garcilaso publica los Comentarios Reales en 1609. Wachtel resume así su visión del Perú:

En definitiva, su utopía integra la cultura inca dentro de una visión occidental de la historia, aunque con un pesar nostálgico la aleje también del presente como paraíso irremediablemente perdido: este doble movimiento explica quizás la extraña fascinación que su obra ha ejercido. (246)

Mientras que Garcilaso es un mestizo de alta cuna, Guamán Poma es un indio puro que pretende descender del Inca Tupac Yupanqui y que ha vivido la explotación colonial en carne viva: de ese modo termina su memorial, que envía a Felipe III en 1614. Guamán Poma percibe el "mundo colonial a través de la óptica del sistema espacio-temporal indígena, y su ideología legitima el retorno a un orden primordial... La reconstrucción de Poma, lejos de caer en algún caos mental, representa lo contrario: una síntesis elaborada según la lógica rigurosa del pensamiento salvaje". Pero la intrusión del sistema de temporalidad occidental amenaza continuamente con desintegrar la síntesis propuesta por Guamán Poma (Id. 262). En ambos casos la aculturación es incompleta y tensa: Garcilaso utiliza el utillaje mental occidental mientras que Guamán Poma recurre al utillaje mental tradicional; Garcilaso desemboca en una visión utópica de ensueño que se desvanece en un tiempo irremediablemente perdido, y Guamán Poma, en cambio, en un programa concreto de reformas que conduce, en su utopía, a la rebelión (263). Así, Garcilaso y Guamán Poma reflejan, de manera muy distinta, el mismo problema social: "una desestructuración sin efectiva reestructuración" (Id. 263).

Con respecto a los procesos de aculturación la conclusión de Wachtel es la siguiente:

La resistencia mayor o menor que oponen las sociedades a la aculturación depende, en la situación colonial, de un conjunto complejo de factores, donde entran a la vez la cohesión de las estructuras tradicionales, la potencia de la dominación extranjera y la elección (o las posibilidades de elección) de los autóctonos entre la resistencia y la colaboración. La oposición entre Garcilaso y Poma, que encarnan los dos tipos de aculturación, se aclara por el simple hecho de que el primero, hijo de un conquistador ilustre, vivió la mayor parte de su vida en España, mientras que el segundo, indio puro, refleja la experiencia directa y concreta de la opresión indígena. Los araucanos pueden adoptar numerosos elementos occidentales porque su resistencia victoriosa permite 
absorberlos sin poner en peligro su cultura original (al precio solamente de una readaptación de la tradición), mientras que los indios del Perú, vencidos, explotados, desposeídos incluso de sus propias instituciones, sólo pueden elegir después del fracaso de las rebeliones entre un rechazo pasivo, una aculturación limitada o, excepcionalmente, la franca asimilación al Occidente. (Wachtel 322)

Entre estos polos de posibilidades, hay, por cierto, un gran número de posibilidades intermedias, pero en la base todo se juega en el "análisis de las lógicas subyacentes y la comprensión de las intenciones que animan a los actores" (322).

Consideremos ahora, como último ejemplo detallado, el caso de un distinguido historiador que como el burgués gentilhombre de Molière, parece trabajar continuamente con la noción de aculturación o transculturación sin saberlo. Me refiero a la tesis doctoral de Tulio Halperín Donghi (2008) sobre el conflicto entre moriscos y cristianos viejos en el reino de Valencia. Se trata de un trabajo publicado en forma completa recién en 1980 pero elaborado en la década de 1950.

El estudio tiene tres partes. La primera desarrolla la situación de la población, la economía y la sociedad entre 1520 y 1609 bajo el título "El lugar de los moriscos en el reino de Valencia". La segunda parte se ocupa de la nación de los moriscos o cristianos nuevos, en un contexto en el que el concepto de nación es utilizado en el sentido que tiene en la época; esto es: como sinónimo de pueblo o grupo étnico. Basándose en una gran cantidad de documentos judiciales, administrativos y eclesiásticos, Halperín reconstruye las diferentes formas de la solidaridad entre los moriscos, que nace y se consolida por medio del contacto entre las aldeas; la circulación creciente de jornaleros, fugitivos y clandestinos, e incluso la presencia de esclavos de la costa norte de África. En la época, la solidaridad religiosa era fundamental ya que "todos los moriscos siguen siendo musulmanes" (Halperín Donghi 87), lo que se refleja en la observación del Ramadán, las cinco oraciones rituales diarias, la práctica de la circuncisión y la persistencia de las tradiciones musulmanas en el momento del casamiento y las ceremonias fúnebres. Asimismo, en las comidas se observa la prohibición del cerdo, los animales se destazan a la manera musulmana y según la Inquisición siguen apareciendo "papeles con letras arábigas". Una de las conclusiones del autor es que "al cabo de noventa años la conciencia de que son musulmanes no ha disminuido; se ha empobrecido enormemente, en cambio, el contenido religioso y cultural de su islamismo" (93-94). La solidaridad religiosa era la base de una solidaridad política y nacional, en el sentido de la solidaridad étnica. Al cabo de noventa años "los moriscos valencianos han 
aprendido que su causa no es ya la del rey de España, que su causa es la de los turcos y los moros de más allá del mar" (116).

La tercera parte estudia las complejas relaciones que se entablan entre los cristianos viejos y los cristianos nuevos o moriscos. ${ }^{5}$ La conversión fracasa y hay diferentes intentos de evangelización, represión y predicación. Al final se produce, como bien se sabe, el decreto de expulsión. "La cabeza de la nación morisca está formada por una asociación de cristianos viejos y nuevos, dirigida, en última instancia, por cristianos viejos" (Halperín Donghi 80). Son precisamente estas relaciones de poder las que es preciso desplegar y analizar para entender a cabalidad las razones y el significado político de la expulsión. En el estudio de Halperín se detallan los fenómenos de aculturación y transculturación, pero nunca se mencionan esos conceptos: el autor se mueve, en cambio, en torno a las redes de solidaridad y el espacio conflictivo del poder. Uno estaría tentado de decir que Halperín practica la sociología de Bourdieu, avant la lettre y, por supuesto, sin siquiera imaginarlo.

\section{V}

Es hora de concluir este recorrido por la historiografía, y de formular algunas conclusiones. Aculturación y transculturación son nociones intercambiables, con la condición de que se defina bien que se trata de procesos de contacto cultural que ocurren en múltiples direcciones y que siempre implican relaciones de poder y de dominación. Su valor conceptual es básicamente heurístico; los antropólogos han provisto catálogos detallados de qué es lo que hay que observar y describir, desde el famoso Memorandum de Redfield, Linton y Herskovits, establecido entre 1935 y 1936. Pero este es apenas el primer paso en el proceso de investigación. El segundo paso, mucho más importante que el anterior, es la consideración del proceso descrito en el marco de las relaciones de poder. Otro ejemplo que se me ocurre como muy significativo es el estudio del candomblé vudú, realizado por Roger Bastide (1996) en las décadas de 1940 y 1950. Tanto las expresiones que tiene en Brasil como en Haití, constituyen ejemplos notables de aculturación o transculturación. Sin embargo, en Brasil el candomblé es una religión conservada que se refugia en la negación de cualquier cambio, debido a la inserción que tiene en las relaciones locales de poder. En Haití, en contraste, el vudú es una religión viva, que se transforma y renueva, en paralelo con los cambios de la sociedad nacional. 
Las nociones de aculturación y transculturación siguen, y seguirán siendo utilizadas en la historiografía y en las ciencias sociales. El concepto de transculturación, menos popular que el de aculturación, ha cobrado nuevos bríos gracias a los estudios culturales y literarios de las últimas décadas (Rama; Pratt). Estos usos hay que verlos, sin embargo, a la par de las nociones de hibridez y heterogeneidad, desarrolladas sobre todo por García Canclini y Cornejo Polar, en sus estudios de 2009 y 2003, respectivamente. Ambos conceptos se agregan como herramientas heurísticas y descriptivas a los de transculturación y aculturación. En la explicación y/o interpretación, la clave sigue siendo la reconstrucción de las relaciones de poder y dominación.

\section{Obras citadas}

Aguirre Beltrán, Gonzalo. El proceso de aculturación y el cambio socio-cultural en México. México: Fondo de Cultura Económica, 1992. Impreso.

Alberro, Solange. Del gachupín al criollo. O de cómo los españoles de México dejaron de serlo. México: El Colegio de México, 1992. Impreso.

Amselle, Jean-Loup. Branchements. Anthropologie de l'universalité des cultures. París: Flammarion, 2001. Impreso.

Amselle, Jean-Loup. Logiques métisses. Anthropologie de l'identité en Afrique et ailleurs. París: Petite Bibliotèque Payot, 2009. Impreso.

Arguedas, José María. El zorro de arriba y el zorro de abajo. Buenos Aires: Losada, 1971. Impreso.

Bastide, Roger. Les Amériques noires. Les civilisations africaines dans le nouveau monde. París: L'Harmattan, 1996. Impreso.

Benedict, Ruth. The chrysanthemum and the sword; patterns of Fapanese culture. Boston: Houghton Mifflin, 1946. Impreso.

Benedict, Ruth. Patterns of culture. New York: New American Library, 1950. Impreso.

Carmagnani, Marcello. El regreso de los dioses. El proceso de reconstitución de la identidad étnica en Oaxaca. Siglos XVII y XVIII.

México: Fondo de Cultura Económica, 1988. Impreso.

Cornejo Polar, Antonio. Escribir en el aire. Ensayo sobre la heterogeneidad socio-cultural en las literaturas andinas. Lima:

CELACP - Latinoamericana Editores, 2003. Impreso.

De Fuentes y Guzmán, Francisco Antonio. Recordación Florida. Discurso historial, natural, material, militar y político del Reino de Goathemala. Ed. Carmelo Sáenz de Santa María. Madrid: Atlas, 1969. Impreso. 
Dupront, Alphonse. "De l'acculturation". XII Congrès International des Sciences Historiques, Vienna 1965. Rapports, Vol. I, Grands Thèmes. Vienna: Ferdinand Berger \& Söhne, 1965. Impreso.

Farris, Nancy M. Maya Society under Colonial Rule. The Collective Enterprise of Survival. Princeton: Princeton University Press, 1984. Impreso.

García Canclini, Néstor. Culturas híbridas. Estrategias para entrar y salir de la modernidad. México: Debolsillo, 2009. Impreso.

Geertz, Clifford. The Interpretation of Cultures. New York: Basic Books, 1973. Impreso.

Gruzinski, Serge. La pensée métisse. París: Fayard, 1999. Impreso.

Halperín Donghi, Tulio. Un conflicto nacional: moriscos y cristianos viejos en Valencia. Valencia: Universidad de Valencia, 2008. Impreso.

León-Portilla, Miguel. Culturas en peligro. México: Alianza Editorial Mexicana, 1976. Impreso.

Martínez Peláez, Severo. La patria del criollo. Ensayo de interpretación de la realidad colonial guatemalteca. Guatemala: Editorial Universitaria, 1970. Impreso.

Ortiz, Fernando. Wifredo Lam y su obra vista a través de sus significados críticos. La Habana: Ministerio de Educación - Dirección de Cultura, 1950. Impreso.

Ortiz, Fernando. Etnia y sociedad. Selección, notas y prólogo de Isaac Barreal. La Habana: Editorial de Ciencias Sociales, 1993. Impreso.

Ortiz, Fernando. Contrapunteo cubano del tabaco y el azúcar. Ed. Enrico Mario Santí. Madrid: Cátedra, 2002. Impreso.

Pratt, Mary Louise. Imperial Eyes. Travel Writing and Transculturation. London: Routledge, 1992. Impreso.

Rama, Ángel. Transculturación narrativa en América Latina. México: Siglo XXI, 1982. Impreso.

Redfield, Robert, Ralph Linton y Melville J. Herskovits. "Memorandum for the Study of Acculturation". American Anthropologist 38.1 (1936): 149-152. Impreso.

Romero, José Luis. La Edad Media. Buenos Aires: Fondo de Cultura Económica, 1987. Impreso.

Socolow, Susan Migden. "La población de la América colonial". Descubrimiento, conquista y colonización de América a quinientos años.

Ed. Carmen Bernand. México: Consejo Nacional para la Cultura y las Artes - Fondo de Cultura Económica, 1994. 218-248. Impreso.

Wachtel, Nathan. Los vencidos. Los indios del Perú frente a la conquista española (1530-1570). Trad. Antonio Escohotado. Madrid: Alianza, 1976. Impreso.

Wachtel, Nathan. "L'acculturation". Faire de l'histoire. Eds. Jaques Le Goff y Pierre Nora. París: Gallimard - Folio, 2011. Impreso. 


\section{Comentario de Vittoria Borsò}

UNIVERSIDAD HEINRICH HEINE, DÜSSELDORF

Con una IRONÍA que recuerda la de Molière, Héctor Pérez-Brignoli vierte una mirada crítica al quehacer de aquellos historiadores que actúan como "bourgeois gentilhommes que hablan de aculturación y transculturación sin saberlo". Por supuesto, no se limita a la ironía, sino que analiza problemas y virtudes de este concepto y su utilidad para la escritura de la historia. Su intención es, pues, diferenciar las premisas implícitas en los discursos históricos o historiográficos. Su propio concepto de transculturación pone de relieve procesos que a) proceden del contacto cultural y ocurren en múltiples direcciones, y b) que siempre implican relaciones de poder y dominación. De esta segunda dimensión se derivan dos tesis: 1) la diferencia existente entre aculturación y transculturación es solo gradual, debido a la interacción que comparten las distintas fases del proceso: deculturación, aculturación, transformación. Justamente esta tesis va en contra del discurso oficial en el que, entre otros, a partir del grito de Arguedas "no soy un aculturado", la aculturación tiene connotaciones negativas. Precisamente para superar la pérdida cultural (deculturación) prevalente en procesos de aculturación, el antropólogo cubano Fernando Ortiz había propuesto la transculturación. 2) El concepto de mestizaje, por otra parte, merece una profunda crítica, pues se refiere no solamente a procesos culturales, sino que describe también situaciones sociopolíticas concretas y desigualdades sociales. Especialmente en México, el concepto de mestizaje es ambiguo incluyendo también una "casta social que adquiere poder". 6

Pérez-Brignoli se vale del estudio de Nathan Wachtel sobre el Perú, quien por su parte demuestra el enraizamiento de Garcilaso Inca de la Vega, mestizo de alta cuna, en el ideario europeo, contrastándolo con la resistencia del indio Guamán Poma, cuyo pensamiento salvaje se basa en la experiencia concreta de la opresión. Pérez-Brignoli dirige luego sus miras a Europa, precisamente al ejemplo de los moriscos en Valencia como modelo de transculturación. Este ejemplo justamente demuestra el efecto destructor del poder dentro de los procesos de transculturación. De hecho, contrario al mantenimiento de rituales religiosos judíos a raíz de la expulsión de España (1492), bajo el poder imperial católico español los moriscos padecen de solidaridad étnica por falta de una comunidad religiosa. Transculturación significa para ellos de-estructuración. Las transformaciones son pérdidas.

6 Coincido con Pérez-Brignoli y remito a mi propia crítica del concepto de mestizaje, especialmente en el contexto mexicano (Ver mi texto de 1994). 
Ahora bien, es importante matizar el poder político, lo que invita a tomar distancia de las euforias transculturales, pues el poder, que domina las prácticas culturales, configura también los procesos de transculturación. No obstante, cabe preguntar acerca del concepto de poder. Como lo demuestra Michel Foucault, el poder no es una máquina metafísica, sino que son prácticas por medio de las que alguien ejerce poder sobre algún otro, lo que permite pensar también en prácticas transversales que impugnan al poder (Guamán Poma). Si, como lo propone Foucault, el poder es un proceso de comunicación, las prácticas lingüísticas de la transculturación son aptas para desestabilizar los fundamentos geopolíticos del poder; es decir, el lenguaje de los binomios, las asimetrías y la orientación (norte, sur, este, oeste), que articula el concepto de lugar mismo, el cual, con la transculturación, padece un quiebre. Esta sería la vía para pensar tanto el entramado político-cultural de la transculturación, como las prácticas transversales de un counterpower. Justamente la escritura (literaria) es un medio que puede poner en marcha dichas funciones subversivas del proceso de transculturación, socavando binomios y semánticas excluyentes. ${ }^{7}$ Estas observaciones nos llevan a revisar el veredicto de Nathan Wachtel acerca de Garcilaso Inca de la Vega. A pesar de su socialización en Europa, al traducir o transponer el saber continental al Perú, la escritura de Garcilaso trastrueca las concretizaciones lingüísticas y las imágenes. ${ }^{8}$ Comentarios reales ya implica una crítica metahistórica y metalingüística, como se nota por ejemplo en la emergente de la anécdota del equívoco lingüístico entre españoles e indígenas - un equívoco en el que los españoles basan su toma de territorio y de sus moradores-:

El Indio, por los ademanes y meneos que con manos y rostro le hacían como a un mudo, entendía que le preguntaban, mas no entendía lo que le preguntaban; y a lo que entendió que era el preguntarle, respondió a presa antes que le hiciesen algún mal y nombró su propio nombre diciendo Berú, y añadió otro y dijo Pelú. Quiso decir, si me preguntáis cómo me llamo, yo me digo Berú; y si me preguntáis dónde estaba, digo que estaba en el río... Los cristianos entendieron conforme a su deseo, imaginando que el indio les había entendido y respondido a propósito, como si él y ellos hubieran hablado en castellano, y desde aquel tiempo, que fue el año de mil quinientos quince o diez y seis, llamaron Perú a aquel riquísimo y grande Imperio, corrompiendo

7 En "Atisbando el futuro" Ernesto Laclau propone trastrocar prácticas políticas por medio de dislocaciones tropológicas del discurso.

8 Lo demostraron, entre otros, Moraña, Glantz y Gruzisnki con respecto al Barroco de las Indias. 
ambos nombres, como corrompen los españoles casi todos los vocablos que toman del lenguaje de los indios de aquella tierra (Garcilaso de la Vega 15-16).

Los potenciales de la escritura transcultural en la formación de un contra-imaginario forjado en oposición al político son eminentes, y nos invitan a reflexionar sobre el poder, al igual que a desplazar los fundamentos epistemológicos tanto de la política de dominación como del correspondiente relato de la historia. De otra manera, los textos serían meras fuentes, pasivos documentos del poder político y de su substancia metafísica.

\section{Obras citadas}

Garcilaso de la Vega. Comentarios reales II. Caracas, Ayacucho: Aurelio Miró Quesada, 1985. Impreso.

Glantz, Margo. Borrones y borradores: reflexiones sobre el ejercicio de la escritura. México: UNAM, Ediciones del Equilibrista, 1992. Impreso.

Gruzisnki, Serge. Les quatre parties du monde. Histoire d'une mondalisation. París: Les éditions de La Martinière, 2004. Impreso.

Laclau, Ernesto. "Atisbando el futuro". Laclau. Aproximaciones críticas a su obra. Eds. Simon Critchley y Oliver Marchart. Buenos Aires: Fondo de Cultura Económica, 2008. 382-383. Impreso. 